\title{
ANÁLISE DOS PROCESSOS PEDAGÓGICOS COM O NOVO MODELO DE GESTÃO EDUCACIONAL: A GESTÃO DA QUALIDADE NA ESCOLA ESTADUAL PROFa ROXANA PEREIRA BONESSI
}

http://dx.doi.org/10.5902/2318133824513

\author{
David de Campos Buás \\ Secretaria Estadual de Educação do Amazonas, Brasil. \\ Secretaria Municipal de Educação de Manaus, Brasil. \\ Viviane Sartori \\ Fundação Universitária Iberoamericana, Brasil.
}

\section{Resumo}

Este texto faz parte da dissertação de mestrado em educação apresentada à Universidade de Jaén/Espanha, em convênio com a Fundação Universitária Ibero-americana/Brasil, que teve como objeto de estudo a análise dos processos pedagógicos com o novo modelo de gestão educacional: a gestão da qualidade na escola estadual Profa ${ }^{-}$Roxana Pereira Bonessi. A pesquisa abordou a influência do modelo de gestão nas mudanças e avanços que a escola teve no período de dez anos em seus processos de gestão e de ensino e aprendizagem, observando o crescimento no Ideb e prêmios no campo da gestão, tendo em vista que esta foi a primeira escola da rede estadual de ensino do Amazonas a implantar o Sistema de Gestão da Qualidade - SGQ e receber o selo de certificação da ABNT NBT ISO 9001:2008.

Palavras-chave: gestão escolar pública, gestão da qualidade, gestão democrática.

\section{ANALYSIS OF EDUCATIONAL PROCESS WITH NEW EDUCATIONAL MANAGEMENT MODEL: QUALITY MANAGEMENT IN STATE SCHOOL PROF ROXANA PEREIRA BONESSI}

\section{Abstract}

This is part of the dissertation in education presented the University of Jaén, Spain, in partnership with the University Foundation Iberoamericana/Brazil, which had as its object of study the analysis of pedagogical processes with the new model of educational management: quality management in state school Prof. Roxana Pereira Bonessi. The study investigated the influence of management changes and advances in the school model had the ten -year period in its process management and teaching and learning, observing the growth in IDEB and awards in the field of management. Given that this was the first state school of Amazonas teaching to deploy the Quality Management System - QMS - to receive the certification seal of ABNT NBT ISO 9001: 2008.

Key-words: public school management, quality management, democracy management. 


\section{Introdução}

ste texto está fundamentado na dissertação de mestrado apresentada ao Programa de Pós-Graduação em Educação da Universidade de Jaén/Espanha, em convênio com a Fundação Universitária Ibero-Americana sede Brasil, como forma de socialização de conhecimentos relevantes ao campo da educação.

O foco da pesquisa foi a gestão escolar, por ser considerada um importante instrumento de mediação nos processos de ensino e aprendizagem e por envolver elementos sociais, políticos e culturais, materializados na realidade da escola e influenciadores da sua forma de organização.

Nesse sentido, este estudo buscou analisar os processos pedagógicos implantados na Escola Estadual de Tempo Integral - ETI - Prof ${ }^{\mathrm{a}}$ Roxana Pereira Bonessi, na cidade de Manaus/Amazonas, especificamente aqueles relacionados ao modelo de gestão educacional ancorado na Gestão da Qualidade Total - GQT.

A escolha da temática se deve aos avanços que a escola teve no período de dez anos nos seus processos pedagógicos e de gestão. Segundo os registros documentais houve um crescimento no Índice do Desenvolvimento da Educação Básica - Ideb - e premiações no campo da gestão, fato que coincidiu com a implantação do horário de tempo integral e da gestão da qualidade.

\section{Gestão escolar pública de qualidade: pontos e contrapontos}

Entender o conceito de qualidade é fundamental quando se pretende trabalhar na perspectiva da gestão. Discuti-lo no âmbito da gestão escolar pública toma dimensão além dos limites conceituais e se contextualiza enquanto concepção teórica.

A gestão escolar pública brasileira tem procurado avançar em uma gestão democrática e de qualidade, ainda que na realidade apresente traços fortes de conservadorismo e práticas autoritárias, distante do que preconizam os incisos VIII e IX do art. $3^{\circ}$ da Lei de Diretrizes e Bases da Educação Nacional que estabelece, dentre outros aspectos, a gestão democrática do ensino público e a garantia de padrão de qualidade.

A presença de traços fortes do conservadorismo e práticas autoritárias deve-se a predominância de uma gestão escolar meramente administrativa denominada de técnicoracional, que se organiza para o "cumprimento de normas administrativas e curriculares de funcionamento, às formas de coordenação e gestão do trabalho dos professores, ao controle dos recursos materiais e financeiros, aos procedimentos administrativos" (Libâneo, 2013, p. 219). Aspectos de uma concepção burocrática funcionalista e produtiva em que prevalecem tomadas de decisões centralizadas, divisão e separação entre o administrativo e o pedagógico e pouca participação da comunidade escolar.

No âmbito da gestão escolar pública, quando analisada com base no conceito de gestão democrática e participativa, tem-se a compreensão de que "a escola é vista como organização social, ou seja, as organizações escolares são unidades sociais, formadas de pessoas que atuam em torno de objetivos comuns" (Libâneo, 2007, p. 220), portanto, como lugar de relações interpessoais democráticas. 
Ambas as concepções, quando comparadas, apresentam suas diferenças quanto à questão da qualidade. A técnico-racional, fundamentada por Libâneo (2013), tem na padronização seu elemento referencial de qualidade estabelecida por um rígido controle e monitoramento das atividades executadas. A gestão participativa tem a democracia como elemento fundamental de qualidade educacional, pois "não há qualidade na educação sem a participação da sociedade na escola" (Gadotti, 2013, p. 2). A democracia no processo educacional é um componente essencial na qualidade na educação, pois, a qualidade para poucos não é qualidade, é privilégio (Gentili, 1995, p. 177).

A gestão da qualidade total da educação se propagou no Brasil nos anos 1990, inserida como componente teórico-ideológico da política econômica neoliberal capitalista, implantada no governo de Fernando Collor de Melo, no período de 1990-1992, chegando ao seu ápice nos dois governos de Fernando Henrique Cardoso, de 1995 a 2002, cujo projeto econômico era reduzir os gastos públicos, privatizar as empresas estatais e diminuir a presença do Estado na economia, denominado de estado mínimo e fortalecer a auto-regulamentação do mercado.

Neste contexto, a GQT foi introduzida como modelo de aplicação gerencial nas empresas privadas, setores administrativos, produtivos e de serviços, com reflexo nos setores públicos. A educação foi um desses setores, por exercer grande importância no quadro dos interesses neoliberais.

A relação estreita da GQT com o neoliberalismo trouxe para o cerne da análise o seu caráter privatizante, aplicado em uma escola pública no Estado do Amazonas como experiência pioneira, onde gerou amplo debate no meio intelectual, reacendendo a discussão das políticas neoliberais na educação.

Ao reeditar e aplicar os princípios e métodos da gestão da qualidade a partir de 2010

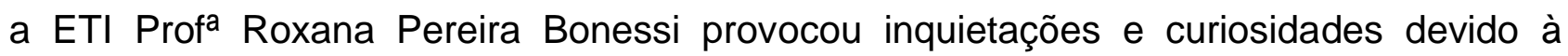
repercussão que o modelo causou nos anos de 1990 na comunidade intelectual e na sociedade civil organizada, seja no que concerne a sua aceitação ou negação. Foi um grande desafio por se tratar de uma concepção de gestão empresarial de caráter privada aplicada em uma escola pública localizada em área periférica de Manaus.

A experiência põe em pauta reflexões sobre a GQT em escolas públicas, pois provocou

implicações para a educação das parcerias entre o público e o privado, nas quais a "propriedade" da educação permanece estatal, mas em muitos casos, o setor privado define sua gestão e o conteúdo do processo educativo, com graves consequências para a autonomia do trabalho docente e a democratização da educação. (Adirão; Perroni, 2009, p.107)

A GQT apareceu no bojo das transformações sociais, políticas e econômicas ocorridas na década de 1990, com fortes tensões sociais pelas precárias condições dos serviços essências prestados pelo Estado, como educação e saúde, em decorrência da implantação da política neoliberal no país. Nesse cenário,

o novo modelo gerou consideráveis melhorias nas formas de gerenciamento das organizações. Infelizmente, o sistema educacional brasileiro não parece ter sido beneficiado por essas mudanças, e os avanços nessa direção têm sido decepcionantes. Quem se dedicar à análise do funcionamento dos sistemas de ensino acabará por encontrar 
provas evidentes de que a gestão é um componente decisivo da eficácia escolar, tão rara de se encontrar no sistema educacional brasileiro, principalmente no ensino fundamental. (Longo, 1996, p. 12)

A autora defende, ainda, que as mudanças começam a ocorrer quando os princípios, conceitos e fundamentos da GQT se integram à cultura da organização, ao dia a dia das pessoas e dos processos organizacionais. Um modelo bem sucedido e exemplo de excelência gerencial nas empresas e que quando aplicado na educação pode contribuir significativamente para a melhoria do ensino no Brasil.

No entanto, o referido modelo antagoniza-se com a concepção democrática e participativa sobre a qualidade da gestão escolar da educação brasileira. Critica-se o modelo por ser um instrumento ideológico do capitalismo liberal, que impõe às escolas e aos sistemas educacionais públicos a aplicação da gestão da qualidade total com os mesmos princípios e métodos administrativos vigentes na empresa capitalista, contrariando as práticas democráticas e educativas que se deseja na escola atual:

Um dos principais objetos de análise dessa crítica é a aplicação da lógica do mercado aos assuntos educacionais que a nova onda, chamada de neoliberal, vem adotando. Todavia, um importante aspecto da adoção de parâmetros neoliberais à gestão escolar que parece não ter merecido ainda a necessária atenção dos especialistas são os efeitos diretos das novas práticas de gestão sobre a formação dos estudantes. Ou seja, tratase de se perguntar em que medida as práticas adotadas ou preconizadas pelos adeptos da "qualidade total", com sustentação na ideologia do liberalismo econômico, carregam consigo um currículo oculto capaz de agir sobre as condutas dos próprios educandos que comungam dos tempos e espaços em que essas práticas se introduzem. (Paro, 1998, p. 2)

O modelo da Gestão da Qualidade Total - GQT -, portanto, tem uma relação com o mercado e com o desempenho qualitativo da educação e, por consequência, sua expansão potencializa o crescimento econômico: "O neoliberalismo formula um conceito específico de qualidade decorrente das práticas empresariais e transferido, sem mediações, para o campo educacional. As instituições escolares devem ser pensadas e avaliadas [...] como se fossem empresas produtivas" (Gentilli, 1998, p. 8).

Na década de 1990 a gestão da qualidade na educação teve ressonância por estar inserida na política neoliberal, principalmente, durante os dois governos de Fernando Henrique Cardoso. A partir de 2002, perdeu relevância no decorrer dos dois mandatos de Luiz Inácio Lula da Silva e no primeiro de Dilma Rousseff, de 2010 a 2014, visto que esses governos representaram uma forte derrota do neoliberalismo e uma intensificação do estado de bem estar social com o fortalecimento das instituições públicas:

A configuração do Estado de Bem-Estar Social em cada país é determinada pelo padrão e o nível de industrialização, a capacidade de mobilização dos trabalhadores, a cultura política de uma nação, a estrutura de coalizões políticas e a autonomia da máquina burocrática em relação ao governo. (Medeiros, 2001, p. 1) 
No entanto, o que diferencia o estado do bem-estar-social de outros tipos como, por exemplo, o estado neoliberal, não é necessariamente a intervenção estatal na economia ou a proteção social com o objetivo de melhorar a qualidade de vida da população, mas, a implantação das políticas públicas e serviços assistenciais promovidos pelo governo como direitos sociais e não como mero assistencialismo.

Em direção contrária às políticas de diminuição dos gastos públicos e privatização, nesses dois últimos governos, com a implantação do estado de bem-estar-social, houve a retomada de uma política de proteção social, quando se estabeleceu a todos os cidadãos brasileiros, dentre outros, as garantias de renda mínima, alimentação, saúde, educação, habitação.

$\mathrm{Na}$ educação básica e superior várias foram as experiências democráticas vivenciadas neste período, com a participação da sociedade e dos segmentos ligados à educação. Nos Estados, Distrito Federal e em diversos e diferentes municípios brasileiros se ampliou o direito à educação, bem como o fortalecimento de uma política educacional sustentada nos princípios da justiça social, igualdade e promoção da cidadania.

Diante desses antecedentes e contexto político educacional a gestão da qualidade total foi implantada na ETI Prof ${ }^{a}$ Roxana Pereira Bonessi, relevando que o modelo, enquanto concepção e proposta de gestão para a educação pública do Amazonas, se manteve ofuscado pelas circunstâncias, mas não superado historicamente.

\section{O funcionamento da gestão da qualidade na ETI Prof ${ }^{a}$ Roxana Pereira Bonessi em Manaus}

Para obter a certificação ISO 9001-2008 da gestão da qualidade a instituição que implanta o modelo adota um rigoroso controle das atividades desenvolvidas em seus setores por meio de um rígido sistema de normas, regras e procedimentos burocráticos administrativos, estabelecidos no Manual do sistema de gestão da qualidade.

Entre as escolas da rede estadual de ensino do Amazonas a ETI Prof ${ }^{\mathrm{a}}$ Roxana Pereira Bonessi foi escolhida, em 2009, pela Secretaria de Educação do Amazonas, em parceria com a Secretaria de Planejamento do Estado, como escola piloto para a implantação do sistema de gestão da qualidade, dentro de uma ação pioneira no sistema estadual público de ensino.

De acordo com os registros no seu projeto político-pedagógico (PPP, 2014), a escola iniciou o processo de implantação do sistema de gestão da qualidade em 2009, atendendo aos requisitos da Associação Brasileira de Normas Técnicas - ABNT - e da International Organization for Standardization - ISO - 9001-2008. Com efeito, cumpriramse todos os procedimentos de implantação do sistema sob a orientação de uma consultoria.

Como ação pioneira na rede estadual de ensino do Amazonas as dificuldades no processo de implantação do sistema de gestão da qualidade foram grandes, em especial por não haver referências anteriores nas escolas públicas do Amazonas. No entanto, o processo de implantação do sistema ocorreu aproveitando as condições físicas e materiais que a escola construída pelo governo do Estado possuía, as experiências e potencialidades profissionais da equipe e a capacidade de liderança da direção.

O sistema da gestão da qualidade foi implantado com o objetivo de organizar e sistematizar a gestão da escola de forma mais ampla e abrangente, indo além dos processos de ensino e aprendizagem e do que rotineiramente se fazia. 
A gestão da qualidade na avaliação da direção fez com que a escola evoluísse muito, não só na questão dos índices do Ideb, mas, também, na questão da formação da equipe para trabalhar e conduzir esse ensino de qualidade. Foi preciso preparar equipe que organizasse os processos pedagógicos, burocráticos da secretaria da escola, da merenda escolar e da área psicológica.

A equipe, então, foi formada e preparada no período de seis meses, no ano de 2010 , para atuar no sistema de gestão da qualidade e, por sua vez, constituir a equipe de auditoria interna. Isso se faz necessário, na concepção do sistema, porque a formação e o comprometimento de todas as pessoas da instituição são aspectos dos mais importantes para o seu funcionamento.

Foi necessário, também, criar os processos por segmentos ou linha de organização dos trabalhos desenvolvidos na escola, cuja formação e preparação da equipe foram direcionadas especificamente para atuar em cada processo. Como uma das exigências a escola editou o seu Manual do sistema de gestão da qualidade ISO 9001:2008, uma espécie de documento orientador e norteador dos procedimentos de gestão da qualidade que, como instrumento de auditoria, é revisado e atualizado sistematicamente na medida em que se alcançam os objetivos e metas estabelecidos no planejamento para garantir continuidade da certificação ISO 9001:2008.

No entanto, no processo de impantação do sistema da gestão da qualidade algumas dificuldades foram encontradas para se aplicar determinados requisitos. Conforme registro no manual, o requisito 7.3 - Projeto e desenvolvimento e seus respectivos subrequisitos de acordo com a ABNT ISO 9001:2008 - não foram aplicáveis na escola.

Esse requisito não é aplicável porque para o sistema, no processo educacional, o produto da escola é a educação medida pela aprendizagem. Entretanto, a aprendizagem se revela no aluno que não é um produto de bem de consumo que pode passar por controle de qualidade na linha de produção, que no final esteja com zero de defeito, sem avarias, sem reprovação ou classificado como produto do tipo $A, B$ ou $C$, como ocorre nas empresas. Na empresa, os serviços nos processos setoriais, passíveis de auditoria, podem corrigir o defeito no produto fabricado na linha de produção, para satisfazer aos clientes. Na escola não é possível transformar o aluno em um produto de consumo.

Como ser humano o aluno apresenta variados tipos de comportamentos, sentimentos, capacidades, habilidades e inteligências e, portanto, não tem 0 mesmo formato moldado em uma única forma, em um único modelo. Nesse sentido, o sistema de gestão da qualidade na escola revela e expõe o paradoxo conceitual: de ser o aluno produto e cliente ao mesmo tempo.

Justificando o paradoxo expõe-se o argumento de que a escola não é fábrica e os alunos não são produtos, por conseguinte, a educação é o produto. Todavia, os clientes para o produto são vários, dentre esses, os próprios alunos, os pais, os futuros empregadores, enfim, a sociedade civil organizada (Tribus, 1992). Tal justificativa pressupõe que os processos de ensino e aprendizagem, bem como seus resultados , não são requisitos diretos de monitoramento e controle na gestão da qualidade na escola, entretanto, para efeito de certificação, ficam inseridos no conjunto do processo educacional. Assim, com exceção e exclusão do requisito 7.3 da ABNT NBT ISO 9001:2008, os demais foram aplicados. 
Nesse sentido, os processos ou serviços da escola, definidos para efeito de monitoramento e controle da qualidade, foram: o pedagógico, o burocrático-administrativo da secretaria da escola, a direção, a alimentação escolar e o psicossocial.

Os processos ou serviços elaboraram seu planejamento, de acordo com os requisitos e normas do GQT, para que a equipe de auditoria interna, composta por um membro de cada processo setorial não encontrasse, na execução das ações, falhas ou erros, ou seja, não conformidades.

Essas auditorias internas são realizadas por pessoal treinado e qualificado ou empresas especializadas, as quais são registradas, levadas ao conhecimento dos responsáveis pelas áreas auditadas e utilizadas como um dos dados de entrada nas análises críticas do sistema de gestão da qualidade. A equipe executa auditorias internas a intervalos planejados para determinar se o sistema de gestão da qualidade está em conformidade com as disposições planejadas nos requisitos da Norma ISO 9001:2008. O responsável pelo setor ou processo auditado deve assegurar que quaisquer ações corretivas sejam executadas em tempo hábil, para eliminar as não conformidades detectadas e suas causas.

No Manual do sistema de gestão da qualidade (2014) da ETI Prof ${ }^{a}$ Roxana Pereira Bonessi (2014) estão definidas as diretrizes que devem ser consideradas pelos processos da escola para cumprimento do padrão normativo NBR ISO 9001:2008. Quanto à organização da gestão o SGQ não alterou a estrutura de gestão da escola, conforme estabelecido pelo sistema de ensino da rede estadual em consonância com o seu regimento.

A direção da escola passou a ter uma denominação de alta direção, que define uma pessoa como sua representante no sistema da gestão da qualidade, denominado de representante da direção que, independentemente de outras responsabilidades, tem autoridade para: a) assegurar que os processos necessários para o SGQ estejam estabelecidos, implantados e mantidos de acordo com a norma NBR ISO 9001:2008; b) relatar o desempenho do SGQ à alta direção e qualquer necessidade de melhoria; c) assegurar a promoção da conscientização dos requisitos do cliente em toda a ETI Prof ${ }^{a}$ Roxana Pereira Bonessi, ou seja, a alta direção é responsável pelo gerenciamento do sistema de gestão da qualidade na escola.

Pelo cumprimento dos requisitos e normas da ABNT NBR ISO 9001:2008, em 22 de junho de 2010, a escola foi certificada com o selo ISO 9001/2008, pela certificadora Bureau Veritas, sendo a primeira escola pública de ensino fundamental do Brasil a ganhar essa certificação.

De 2010 a 2013 a escola manteve todos os requisitos de padrão da gestão da qualidade, sem ter sofrido o processo de follow-up - nova oportunidade ou chance - ou perda da certificação, ainda que nesse período algumas não conformidades ocorressem em processos setoriais. Por isso, em 30 de setembro de 2013, foi recertificada, desta feita pela certificadora TUVRheinland, mantendo a referida certificação em 2014.

\section{A relação do novo modelo com os do ensino e aprendizagem da escola}

Após um ano de sua inauguração a escola participou, em 2005, de sua primeira avaliação externa por meio da prova brasil, com duas turmas do $5^{\circ}$ ano do ensino fundamental. Como foi a primeira participação da escola na referida prova o resultado, conforme o Ideb foi de 3.3, equivalendo à média estadual de 3.3. 
A escola se reestruturou pedagogicamente, transformando-se em escola de tempo integral em 2007, oferecendo turmas no $1^{\circ}$ e $2^{\circ}$ anos do ensino fundamental, organizado em ciclos, além de turmas no ensino médio, por isso, não participou da segunda edição da Prova Brasil.

$\mathrm{Na}$ terceira edição da Prova Brasil, em 2009, voltou a participar e o resultado, conforme o Ideb, foi 5.3, ultrapassando a meta estadual 4.5 , bem como a meta federal de 3.7.

$\mathrm{Na}$ quarta edição, em 2011, a escola alcançou a média 6.3, ultrapassando novamente a média de 4.8 e a meta estadual de 5.5, tal qual a meta federal de 4.4, enquanto, na quinta edição, em 2013, alcançou a média 6.6, acima da média 5.1 e meta estadual de 5.5

Considerando somente as quatro edições da Prova Brasil, visto que em 2007 a escola não participou, constata-se em termos percentuais que, entre os anos de $2005 \mathrm{e}$ 2013, a escola teve um crescimento de $100 \%$ nos resultados do Ideb, passando de 3.3 de média em 2005 para 6.6 em 2013, última edição analisada.

Entretanto, se observado apenas o crescimento proporcional, o maior ocorreu entre anos de 2005 e 2009, quando a escola passou de 3.3 para 5.3 respectivamente, crescendo 2.0 pontos equivalentes a $61 \%$. Entre os resultados alcançados nas edições da Prova Brasil de 2009 e 2011 a escola passou de 5.3 para 6.3, crescendo um ponto, equivalente a $20 \%$ e, entre 2011 e 2013 , a escola avançou apenas 0.3 , o que equivale a $5 \%$, pois passou de 6.3 para 6.6 .

Quando se agregam outros elementos de análise nesse contexto, como o número de aprovados, reprovados e evadidos, conforme o rendimento escolar final dos anos iniciais do ensino fundamental de 2004 a 2014, as evidências confirmam os avanços nos processos de ensino e aprendizagem, ou seja, não só os índices do Ideb cresceram como, a partir de 2007 , chegou a zero o número de reprovados e dos que abandonaram a escola ao longo desse período.

Considerando que em 2007 a escola passou a funcionar em tempo integral e, em 2010, implantou a gestão da qualidade, as evidências de melhorias são significativas nesses processos. Ressalte-se que mesmo com os percentuais menores entre $2009 \mathrm{e}$ 2011 e 2011 e 2013, a escola continuou em crescimento e com uma contínua progressão, comparando-se com as metas estadual e federal.

Constata-se, portanto, que houve significativa melhoria nos processos de ensino e aprendizagem com a implantação do tempo integral na escola, nesses períodos. Entretanto, considerando especificamente os processos de ensino e aprendizagem não se pode atribuir diretamente à influência da gestão da qualidade nessas melhorias, não pelos resultados pura e simplesmente revelados nos dados, que não deixam de ser uma evidência, mas, pelo que a gestão da qualidade estabeleceu como requisito de controle e monitoramento nesses processos.

$\mathrm{Na}$ implantação da GQT na escola houve a impossibilidade de ser aplicado o requisito 7.3 da ABNT NBT ISO 9001:2008, fato que gerou um conflito na concepção entre os consultores externos e a equipe da escola pela dicotomia sobre o que seria 0 produto da escola para efeito de controle e monitoramento nos processos pedagógicos: 0 aluno ou a aprendizagem? Entendimento diferente do que afirma Tribus (1992), como já exposto. 
Para o referido autor a educação oferecida é que é o produto da escola, enquanto que os clientes ou usuários desse produto são os próprios alunos, os pais, os futuros empregadores, a sociedade em geral.

Diante desse impasse, dentro do serviço ou processo pedagógico, o ensino e a aprendizagem não foram incluídos para efeito de controle e monitoramento da GQT na escola, ou seja, não foram passíveis de auditoria e, portanto, não foram considerados serviços diretos e específicos para efeito de certificação ABNT NBT ISO 9001:2008.

Com isso pode-se afirmar que os resultados inerentes ao ensino e a aprendizagem provenientes do trabalho didático-pedagógico do professor em sala de aula, que reflete nos indicadores do Ideb, bem como no rendimento final dos alunos, não tiveram influência direta da gestão da qualidade quanto ao crescimento e melhorias respectivamente, indicando uma influência maior do tempo integral implantado na escola a partir de 2007.

O que interessa a GQT para efeito de auditoria nos serviços ou processos pedagógicos no âmbito escolar é a parte documental como o planejamento, o diário digital, frequência, o conteúdo aplicado, aula previstas, aulas dadas, ou seja, os aspectos quantitativos, onde se podem verificar evidências de execução das tarefas planejadas.

\section{Conclusão}

A gestão da qualidade na educação não é um fenômeno novo ou inédito. O que se considera como nova é sua reedição depois de duas décadas em uma escola pública da rede estadual de ensino do Amazonas, na cidade de Manaus, em circunstâncias, de certa forma, desfavoráveis em relação aos anos 1990, pois a atual conjuntura política da educação brasileira aponta para proposituras e paradigmas que preconizam 0 fortalecimento da qualidade do ensino público com gestão democrática-participativa.

A gestão da qualidade implantada na ETI Prof ${ }^{a}$ Roxana Pereira Bonessi é uma experiência única, sem precedentes, sem referências anteriores, pois se trata da primeira escola a aplicar o modelo e possuir o selo de certificação da ABNT ISO 9001:2000 na rede pública estadual de ensino do Amazonas.

Os resultados desvelados com o funcionamento do sistema na escola não apresentam indícios ou intencionalidades de privatização da escola ou de sua gestão - o que não significa que não seja possível - e por extensão da rede de ensino, ainda que, ao ser implantado, induziu a gestão da escola a adotar uma concepção gerencial como empresa privada. São resultados de ordem programáticos e pragmáticos aplicados em uma escola pública, sem apresentarem mudanças ou rupturas com o modelo existente, pois a concepção adotada na maioria das escolas da rede estadual de ensino do Amazonas tem como predominância a concepção tecnicista, na qual a gestão da qualidade se enquadra. Neste caso, portanto, não houve incompatibilidade entre o sistema da gestão da qualidade e os processos pedagógicos e operacionais da Secretaria de Educação do Amazonas, visto que um não invalida o outro por inexistência do contraditório e por se enquadrarem no mesmo campo de concepção teórica.

O que mudou com a implantação da gestão da qualidade foi a forma de organizar a gestão e de sistematizar as ações pedagógicas, administrativas e operacionais, denominadas de serviços e processos pelo sistema de gestão da qualidade. Ao enfatizar teoricamente a participação, não significa que na prática, esta seja democrática, porque o princípio da participação na gestão da qualidade está relacionado com a resolução de problemas no processo produtivo, no caso das instituições escolares nos processos 
setoriais, e não, necessariamente, em uma forma coletiva de tomada de decisões, visto que as relações de poder são hierarquizadas e as decisões finais centralizadas no diretor, alta direção, prevalecendo às relações de subordinação, tendo em vista que uns têm mais autoridade que outros em uma forma de administração sob controle.

Quanto à valorização dos profissionais a gestão da qualidade tem como princípio a valorização do desempenho individual e não coletivo, pois privilegia os cargos ou funções de liderança, expressados na hierarquização e decisões setoriais verticalizadas.

A implantação do modelo na escola se relevou na constituição das equipes de auditoria interna, composta por um membro de cada processo setorial, que junto com a alta direção monitora a execução das ações e apresenta um relatório à equipe de auditoria externa pertencente a uma consultoria especializada privada, contratada pelo governo do Estado, prevalecendo, com isso, a gestão de decisões hierarquizadas e os procedimentos, tarefas, regulamentados por normas e regras de controle burocrático, dando-se mais importância para as tarefas do que para as pessoas.

Uma gestão participativa sustentada na concepção democrático-participativa baseiase na relação orgânica entre direção e a participação dos membros da equipe, e acentua a importância da busca de objetivos comuns assumidos por todos.

Portanto, a participação e a valorização dos profissionais preconizadas pela concepção da gestão da qualidade, excetuando as semelhanças conceituais, não têm similaridade, proximidade e compatibilidade com as concepções de gestão escolar democrática e participativa. No entanto, considerando somente os aspectos programáticos e pragmáticos no funcionamento do modelo na escola, o processo de padronização foi relevante.

Quando se afirma que as mudanças ocorridas com a gestão da qualidade foram na forma de padronizar a gestão com organização e sistematização das ações pedagógicas, administrativas e operacionais chamadas de serviços e processos significa dizer que a escola teve avanços nesse aspecto. A ênfase na gestão e procedimentos regulados com um sistema de normas, regras e procedimentos burocráticos de controle das atividades, na escola ETI Prof ${ }^{a}$ Roxana Pereira Bonessi, com gestão da qualidade, foi, efetivamente, um diferencial.

Outros aspectos, de ordem protocolar exequível em qualquer modelo de gestão escolar, também foram considerados relevantes para o funcionamento do modelo na escola, como o convencimento, envolvimento e compromisso de todos os docentes e funcionários e a formação técnica de lideranças para conduzir as auditorias internas; apropriação do conhecimento teórico, prática do modelo e capacidade e habilidade política da direção.

Portanto, a implantação da gestão da qualidade na ETI Prof ${ }^{a}$ Roxana Pereira Bonessi serve de reflexão e, concretamente, como parâmetro para definição de modelos de gestão escolar, bem como o padrão de qualidade que se deseja para a escola pública brasileira. Decerto, a gestão escolar pública é um vasto caminho a ser percorrido no campo da investigação. Este trabalho analisou uma experiência, porém, faz-se necessário avançar ainda mais na investigação desta e de outras experiências concretas para se ampliar o leque de possibilidades e viabilidades de aplicação na prática. 


\section{Referências}

ADRIÃO, Theresa; PERONI, Vera Maria Vidal. A educação pública e sua relação com o setor privado: implicações para a democracia educacional. Retratos da Escola, Brasília, v. 3, n. 4, 2009, p. 107-116.

BRASIL. Lei de Diretrizes e Bases da Educação Nacional: nova LDB (lei n. 9.394/96). Rio de Janeiro: Qualiltymark, 1997.

ESCOLA DE TEMPO INTEGRAL PROFa ROXANA PEREIRA BONESSI. Projeto políticopedagógico. Manaus: ETI Prof ${ }^{\underline{a}}$ Roxana Pereira Bonessi, 2014.

GADOTTI, Moacir. Qualidade na educação: uma nova abordagem. CONGRESSO DA EDUCAÇÃO BÁSICA: QUALIDADE NA APRENDIZAGEM, 2013. Anais ... Florianópolis: Prefeitura Municipal, 2013.

GENTILI, Pablo. Neoliberalismo, qualidade total e educação: visões críticas. Petrópolis: Vozes, 1998.

LONGO, Rose Mary Juliano. Gestão da qualidade: evolução, histórica, conceitos básicos e aplicação na educação. Brasília: MEC, 1996.

LIBÂNEO, José Carlos. Organização e gestão da escola: teoria e prática. São Paulo: Heccus, 2013.

LIBÂNEO, José Carlos. Concepções e práticas de organização e gestão da escola: considerações introdutórias para um exame crítico da discussão atual no Brasil. Revista Española de Educación Comparada. Madrid, n. 13, 2007, p. 155-192.

MEDEIROS, Marcelo. Trajetória do welfare state no Brasil: papel redistributivo das políticas sociais dos anos 1930 aos anos 1990. Brasília: Ipea, 2001.

PARO, Vitor Henrique. Gestão escolar, democracia e qualidade no ensino. Paulo: Ática, 1998.

PARO, Vitor Henrique. A gestão da educação ante as exigências de qualidade e produtividade da escola pública. In: SILVA, Luiz Heron da (org.). A escola cidadã no contexto da globalização. Petrópolis: Vozes, 1998, p. 300-307.

SUÍÇA. International Organization for Standardization, ou Organização Internacional para Padronização. ISO, entidade de padronização e normatização, Genebra, Suíça, 1947.

TRIBUS, Myron. Quality management in education. [S.I.]: Eric Education Resources Information Center, 1992. Disponível em <http://www.eric.ed.gov/ERICWebPortal/ search/detailmini.jsp? _nfpb=true\&_\&ERICExtSearch_SearchValue_0=ED371441\&ERICE xtSearch_SearchType_0=no\&accno=ED37144>. Acesso em 22 jun. 2016.

David de Campo Buás é mestre em educação pela Universidade Jaén/Espanha, convênio com Fundação Universitária Ibero-americana, sede Brasil. integrante efetivo da Comissão de Acompanhamento e Monitoramento do Plano Estadual de Educação. Professor da Secretaria de Educação do Estado do Amazonas e da Secretaria Municipal de Educação de Manaus.

Endereço: Rua Lopo Soares, quadra 19, n. 168 - 69.077-840 - Manaus - AM - Brasil.

E-mail: davidbuas@seduc.net. 
Viviane Sartori é pedagoga e mestre em Engenharia e Gestão do Conhecimento pela Universidade Federal de Santa Catarina. Estudante do curso de doutorado no mesmo programa. Consultora na Fundação Universitária Ibero-americana, sede Brasil.

Endereço: Rodovia Amaro Antônio Vieira, 2108 - 88.034-102 - Florianópolis - SC Brasil.

E-mail: vivi.sartori19@gmail.com.

Recebido em 18 de outubro de 2016.

Aceito em 4 de dezembro de 2016. 